\title{
Some things to worry about
}

\author{
Fiona Godlee editor, BMJ
}

\begin{abstract}
About one in 20 people will suffer from generalised anxiety disorder in their lifetime, but, according to the authors of this week's Clinical Review, the condition is not well recognised in primary care (doi:10.1136/bmj.e7500). This matters because there are effective treatments that can improve quality of life and reduce the risk of major depression. Sufferers are often heavy users of primary care, so tackling underlying anxiety may reduce the burden on overstretched health services.
\end{abstract}

NICE guidance last year recommended a stepped care approach with a combination of drug and psychological treatments $(B M J$ 2011;342:c7460). In addition, Hoge and colleagues emphasise physical exercise, sleep hygiene, and mindfulness training, all of which are supported by a growing evidence base.

Mindfulness training has long been recommended for the treatment of depression. It first featured in NICE guidance nearly 10 years ago and was listed as a key priority in NICE's 2009 update. In their Uncertainties Page this week, Willem Kuyken and colleagues ask "Does mindfulness based cognitive therapy prevent relapse of depression?" (doi:10.1136/bmj.e7194). From the evidence they cite, the answer seems to be a clear "yes." So what's the uncertainty? They argue that we don't yet know how mindfulness compares with other psychological therapies, or with maintenance drug treatment, whether using both together is more beneficial than either alone, or how acceptable and feasible this approach is for a broad base of patients at risk of relapse. Fortunately several trials are under way that should give us answers to these questions.

Meanwhile, in case you didn't have enough to worry about, here are some things that may not have occurred to you. Firstly, is the men's health campaign Movember misleading men?
Margaret McCartney says it is (doi:10.1136/bmj.e8046). Its narrow focus on screening for prostate cancer is not evidence based, she says, and the campaign is all but silent on more pressing concerns of mental illness, alcohol and substance misuse, smoking, and obesity.

Secondly, are we doing enough to protect the interests of future generations? Hilary Graham says we aren't (doi:10.1136/bmj. e7573). Public health has a duty to protect the conditions for health over time and across generations. But environmental degradation is bringing 10000 years of biophysical stability and human flourishing to an abrupt end, she says. In this context, current generations are "the advantaged minority, and the disadvantaged majority are those yet to be born." She calls for an urgent rethink that ensures equity across generations. Public health should be "the voice of the disenfranchised populations of the future."

Finally, why are we so poor at generating new hypotheses? The current system is haphazard and plays it safe, says Frank Davidoff, by "testing endless variations of the hypothesis that 'drug X affects outcomes in disease Y'" (doi:10.1136/bmj. e7991). He would like to see the clinical research community affirming the vital role of hypothesis generation, and he proposes a Grand Jury system for judging which well founded falsifiable hypotheses should be properly tested. Those in charge of assessing, ranking, and rewarding researchers and their institutions (doi:10.1136/bmj.e7797) should take note.

Cite this as: BMJ 2012;345:e8125

๑ BMJ Publishing Group Ltd 2012 